Confederation Negotiating Team (now CEO NHS north west [SHA]) said:

PRICCE practices have shown that where effort is targeted they have met with considerable and sometimes unexpected success. This has demonstrated that it is unwise to underestimate what is possible. I commend this project to you as a good working example of how to implement the Quality and Outcome Framework of the GMS2 contract.

I suggest it is time recognition was given where it is due.

\section{John Ashton,}

Retired GP and Late Medical Secretary to the East Kent Local Medical Committee, Orchard House, Somerset, TA14 6SN.

E-mail: Ashton.john@btinternet.com

\section{REFERENCES}

1. Ashworth M, Kordowicz M. Quality and outcomes framework: time to take stock. Br J Gen Pract 2010: 60(578): 637-638.

2. Rowland M. Linking physicians' pay to the quality of care - a major experiment in the United Kingdom. $N$ Eng J Med 2004; 351(14): 1448-1154.

3. Spooner A, Chapple A, Rowland M. What makes British general practitioners take part in a quality improvement scheme? J Health Serv Res Policy 2001; 6(3): 145-150.

DOI: 10.3399/bjgp10X538976

\section{NHS}

Your comments regarding the latest restructuring and the need instead for a serious consideration of a new approach to funding struck a note of clarity, at long last, in the debate about how best to make the NHS more efficient and effective. ${ }^{1}$ I have spent most of my working life under the aegis of the NHS in Northern Ireland, but have many family members in the Republic of Ireland, and while its system of health care has its own problems, the insurance-based funding ensures that both consumers (patients) and providers (health professionals) are made very aware of the actual costs of treatment. The patients may (and often do) obtain reimbursement but the message is clear. I acknowledge that there are significant transactional costs in such schemes but until we can depart from the Holy Grail of a comprehensive 'cradle to grave' service, also 'free at the point of use', no amount of restructuring will address the need for all parties in the NHS to use the service in the most effective way. I hope sincerely that your excellent article is read by those in the medico-political arena, the NHS as it stands is indeed both uncontrollable and now unaffordable.

\section{Denis Boyd,}

Retired GP, 31 Lislunnan Road, Kells, Ballymena, County Antrim, BT42 3NR E-mail: denis.boyd2@btinternet.com

\section{REFERENCE}

1. Jones R. The White Paper: a framework for survival? Br J Gen Pract 2010; 60: 635-636.

DOI: 10.3399/bjgp10X538985

\section{Colour vision problems}

I read with interest the correspondence from Jayakrishnan and Al-Rawas on the use of universal dots to colour code and identify asthma inhalers. ${ }^{1}$

I appreciate the authors' desire to ensure a universal and consistent system but, unfortunately, the interpretation of colours is fraught with complication. The problem of colour vision deficiency has been known since John Dalton first described the condition in $1798 .{ }^{2}$ Some $8 \%$ of men and $0.5 \%$ of women have some degree of a problem, that is an estimated 2.4 million men in the UK alone. Red-green colour vision deficiency is the most common and brown is a colour where particular difficulty is encountered.

The problems with colour vision deficiency have been documented but continue to be generally under-appreciated in the medical environment, for example, there is good evidence that doctors and patients can struggle to spot red rashes. ${ }^{3}$ Those with colour vision deficiency can also fail to recognise blood in bodily fluids and this has translated into evidence that those with colour vision deficiencies are more likely to present with late stage bladder cancer. ${ }^{5}$

I would plead the case on behalf of those of us who are colour blind and I would resist the use of colour in the identification of medicines. In the diagram I was unable to differentiate between the brown, green, or red universal dots. It is particularly challenging to identify small dots or bands of colour, and great care needs to be taken in assigning surface colour codes as those with colour vision deficiencies are prone to error, particularly under lower levels of illumination. ${ }^{6}$

\section{Euan Lawson,}

E-mail: euanlawson@googlemail.com

\section{Competing interest}

I have been confirmed as having protanopia and it is clearly not in my personal interest to see the increasing use of colour coding.

\section{REFERENCES}

1. Jayakrishnan B, Al-Rawas OA. Asthma inhalers and colour coding: universal dots. Br J Gen Pract 2010; 60(578): 690-691.

2. Dalton J. Extraordinary facts relating to the vision of colours: with observations. Memoirs of the Literary Philosophical Society of Manchester, 1798. 5: 28-45.

3. Spalding JA. Confessions of a colour blind physician. Clin Exp Optom 2004; 87(4-5): 344-349.

4. Reiss MJ, Labowitz DA, Forman S, et al. Impact of colour blindness on recognition of blood in bod fluids. Arch Intern Med 2001; 161(13): 461-465.

5. Katmawi-Sabbagh S, Haq A, Jain S, et al. Impact of colour blindness on recognition of haematuria in bladder cancer patients. Urol Int 2009; 83(3): 289-290.

6. Cole BL. The handicap of abnormal colour vision. Clin Exp Optom 2004; 87(4-5): 258-275.

DOI: 10.3399/bjgp10X538994

\section{Authors' response}

We understand clearly the concern raised by Lawson. Our aim is not to substitute the labelling of the drugs with colour coding, but to suggest uniformity for the existing colour selection of the inhaler's casing. ${ }^{1}$ Often the patients are instructed to take the 'blue inhaler' in case of need and to use the 'purple or red inhalers' regularly, rather than identifying them by the drug names. Instead, they could now be asked to take the 'blue dot inhaler' in case of need and to use the 
'brown-yellow dot inhaler' regularly.

Colour has always been used to aid recognition, this convention is not new in medicine. A standardised colour code for user-applied syringe labels for anaesthetic drugs exist in the US, Australia, New Zealand, South Africa, and Canada. ${ }^{2} \mathrm{~A}$ single standard system for syringe labelling in critical care areas has been adopted in the UK as well. ${ }^{3}$

There is always a problem in reading the labels as instructions are often written at a level too complex for low literacy patients. ${ }^{4,5,6}$ Inadequate literacy, without any doubt, is a barrier to asthma knowledge and proper self-care. ${ }^{6,7}$ Moreover, patients who have a different first language than the healthcare provider can raise additional issues.

So there will be a large group of patients who can identify their inhalers only by the colour. Older people who have difficulty identifying colours will have difficulty reading fine print as well and will need assistance. People who are colour blind should continue to read the labels or identify their inhalers by the design or size. We, therefore, believe that adding universal colour dots to the current system will only do good in creating uniformity without causing any additional limitations.

\section{B Jayakrishnan,}

Consultant, Department of Medicine,

Sultan Qaboos University, Oman.

E-mail: drjayakrish@hotmail.com

\section{Omar A Al-Rawas,}

Associate Professor, Department of Medicine, Sultan Qaboos University, Oman.

\section{REFERENCES}

1. Jayakrishnan B,Al-Rawas OA. Asthma inhalers and colour coding: universal dots. Br J Gen Pract 2010; 60(578): 690-691.

2. Christie IW, Hill MR. Standardized colour coding for syringe drug labels: a national survey. Anaesthesia 2002; 57(8): 793-798.

3. Carter JA. Syringe labelling in critical care areas. June 2004 Update. RCoA Bulletin 2004; 27: 1370-1373.

4. Davis TC, Crouch MA, Wills G, et al. The gap between patient reading comprehension and the readability of patient education materials. J Fam Pract 1990; 31(5): 533-538.

5. Goodyer L, Savage I, Dikmen Z. Inhaler technique in Turkish people with poor English: a case of information discrimination? Pharm World Sci 2006; 28(2): 107-114

6. Williams MV, Baker DW, Honig EG, et al. Inadequate literacy is a barrier to asthma knowledge and self-care. Chest 1998; 114(4): 1008-1015.

7. Sestini P, Cappiello V, Aliani M, et al. Prescription bias and factors associated with improper use of inhalers. $J$ Aerosol Med 2006; 19(2): 127-136.

DOI: 10.3399/bjgp10X539001

\section{Visual loss}

We would like to highlight the problems that patients with significant visual loss have in detecting clinically important signs. Two male patients aged 71 and 75 years, who were registered blind due to retinitis pigmentosa, were late presentations with bladder carcinoma. It was clear that these patients had haematuria for some time prior to presentation but were unable to detect this due to severe visual loss.

The purpose of this letter is to draw attention to the difficulty that patients with visual loss have in detecting signs that are easily apparent to patients without visual loss.

It is difficult to see how these problems can be avoided. One suggestion would be a protocol in place where patients who are placed on the Blind Register and their relatives are advised on their inability to detect clinical signs such as haematuria, malaena, and haemoptysis and therefore need regular assessment by a third party to detect such signs.

\section{Ahmad Khalil,}

Southport and Ormskirk NHS Trust Hospitals. E-mail: ahmadkhali__61@hotmail.com

Niall O'Donnell,

Southport and Ormskirk NHS Trust Hospitals.

DOI: 10.3399/bjgp10X539335

\section{The physician assistant}

In answer to Olumide Elegbe's question 'is there a role for physician assistants (PAs) in routine care?"1 my answer, currently, would be no. I would much prefer an experienced nurse or even, dare I suggest it, another doctor. Mr Elegbe obviously has confidence in the evidence he has referenced, however, the majority of this is from the US and given the differences between our two healthcare systems and respective primary care, I would not rush to apply the same conclusions from the data collected there, to here.

A pilot of PAs has already been undertaken in Scotland ${ }^{2}$ and this highlighted some important points. The PAs involved felt that they were unable to demonstrate their full capacity within primary care and this was attributed to the fact that there was no identifiable gap in the care of patients for them to fill, presumably this was because the preexisting primary care team was already sufficient and as the PAs put it 'family medicine/general practice differed from the US to Scotland'.

Any issue regarding the costeffectiveness of PAs was also underlined by the study, reporting that within the primary care setting, an individual PA would cost approximately $£ 15000$ more to employ than a practice nurse (PA salary defined as Agenda for Change Band 7, £29 091-£38 353).

I remain unconvinced that a science graduate with 2 years training would complement the current primary care team, at least not for that price.

\section{Stuart Vas,}

GP, Penistone Group Practice,

19 High Street, Sheffield, S36 6BR.

E-mail: sjvas@doctors.org.uk

\section{REFERENCES}

1. Elegbe O. GP commissioning consortia: is there a role for physician assistants in routine care? Br J Gen Pract 2010; 60(578): 704-705.

2. Farmer J, Currie M, West C, et al. Evaluation of physician assistants to NHS Scotland. Final report. UH Millenium Institute, 2009 . http://www.abdn.ac.uk/crh/uploads/files/PA\%20Final\% 20report\%20Jan\%2009\%20version\%205.pdf (accessed 8 Oct 2010).

DOI: 10.3399/bjgp10X539344

\section{Antidepressant prescribing}

The appropriateness of antidepressant 